\title{
A New Species and Complements to the Descriptions of Nine African or Oriental Dicranocentrus (Collembola: Entomobryidae) ${ }^{1,2}$
}

\author{
José A. Mari Mutt ${ }^{3}$ \\ ABSTRACT
}

Dicranocentrus delamarei n. sp. from Ivory Coast is described and differentiated from its closest relatives: D. gracilis Schott and D. colombiensis Mari Mutt. The generic position of D. stachi (Denis), a species previously placed in two other genera, is discussed. Details are added to the descriptions of the following nine African or Oriental Dicranocentrus species: meruensis, longicornis, assimilis, orientalis, inermodentes, solomonensis, lawrencei, and spinosus.

\section{INTRODUCTION}

Soon after the revision of Dicranocentrus Schött (6) went to the printers, a revision of the scaled. Orchesellinae was undertaken. In order to separate species of other genera in this subfamily, it was imperative for the writer to study a series of characters not taken into consideration during the study of Dicranocentrus.

This paper presents the results of a new study of the specimens kept at the Illinois Natural History Survey, Urbana, Illinois (6), as well as of additional material received recently.

\section{RESULTS}

\section{Dicranocentrus delamarei N. SP.}

Habitus typical of genus. Length up to $2.9 \mathrm{~mm}$. Traces of violet pigment on antennae, anterior portion of head, and legs except on coxae. Ratio of Ant. 5 to Ant. 6 unknown. Dorsal head macrochaetotaxy as in figure 1. Labral papillae of type I (fig. 5). Chaetotaxy of labial triangle as in figure 3. Subapical seta of maxillary palp similar in shape but longer than apical seta (fig. 4). All setae of venter of head smooth. Tibiotarsi without smooth setae. Structure of claws as in figure 2. Tenent hair apically clavate.

${ }^{1}$ Manuscript submitted to Editorial Board March 6, 1980.

${ }^{2}$ This paper is based, in part, on a thesis deposited by the author in the Graduate College of the University of Illinois at Urbana-Champaign in partial fulfillment of the requirements for the degree of Doctor of Philosophy, Entomology, 1978.

${ }^{3}$ Department of Biology, University of Puerto Rico, Mayagüez, Puerto Rico 00708. The author expresses his gratitude to the staff of the Faunistics Section of the Illinois Natural History Survey for their encouragement and support during his stay there. Thanks are also due to Dr. Judith Najt, Université Paul Sabatier, Toulouse, France, for the loan of the holotype of Dicranocentrus stachi, and to Mr. Peter N. Lawrence, British Museum (Natural History) for the loan of a paralectotype of $D$. longicornis. 


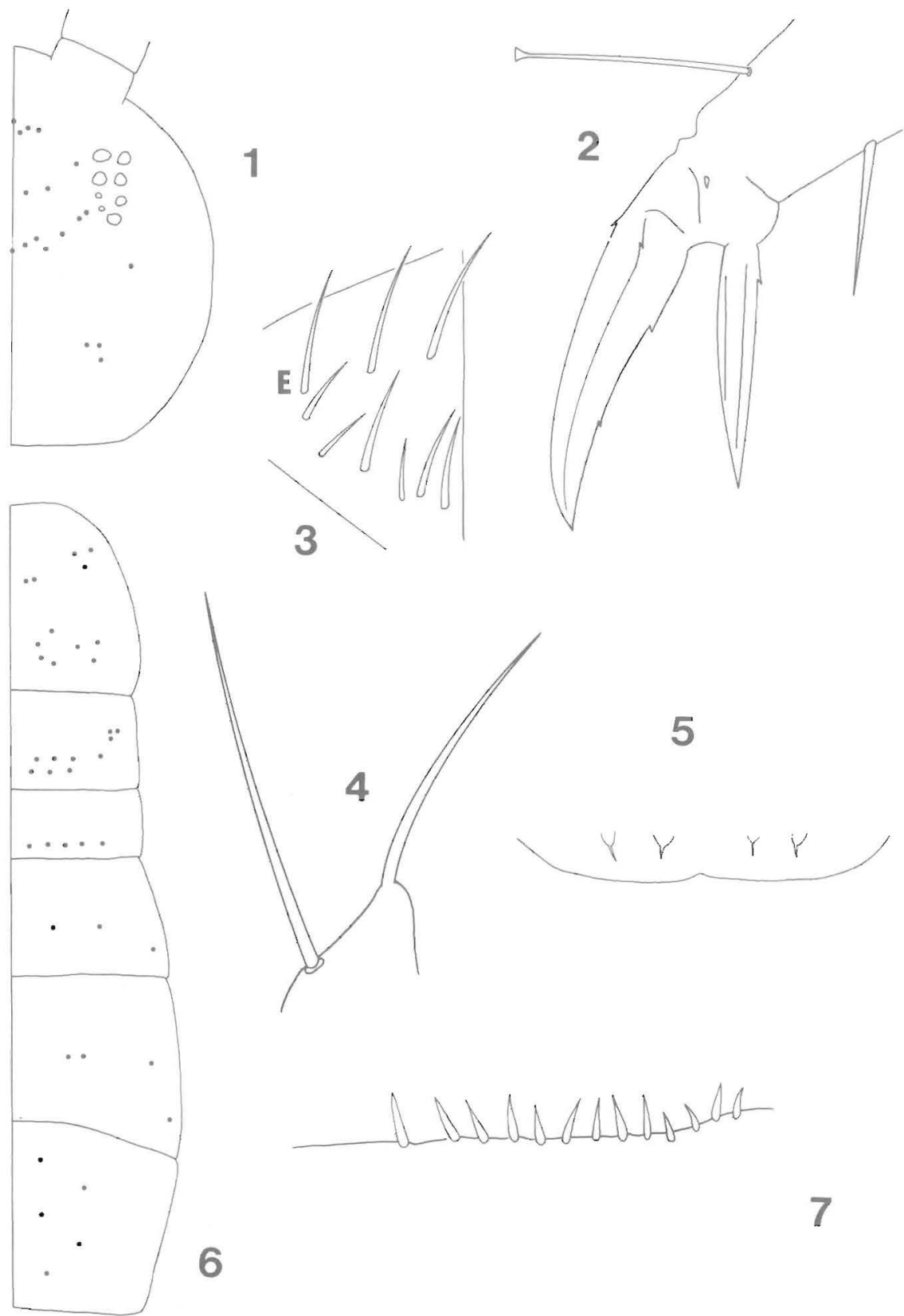

Plate I, Figs. 1-7-D. delamarei n. sp. 1. Dorsal head macrochaetotaxy. 2. Metathoracic claws. 3. Chaetotaxy of labial triangle. 4. Maxillary palp. 5. Labral papillae (Type I). 6. Dorsal body macrochaetotaxy. 7. Dental spine arrangement, dorsal view. 


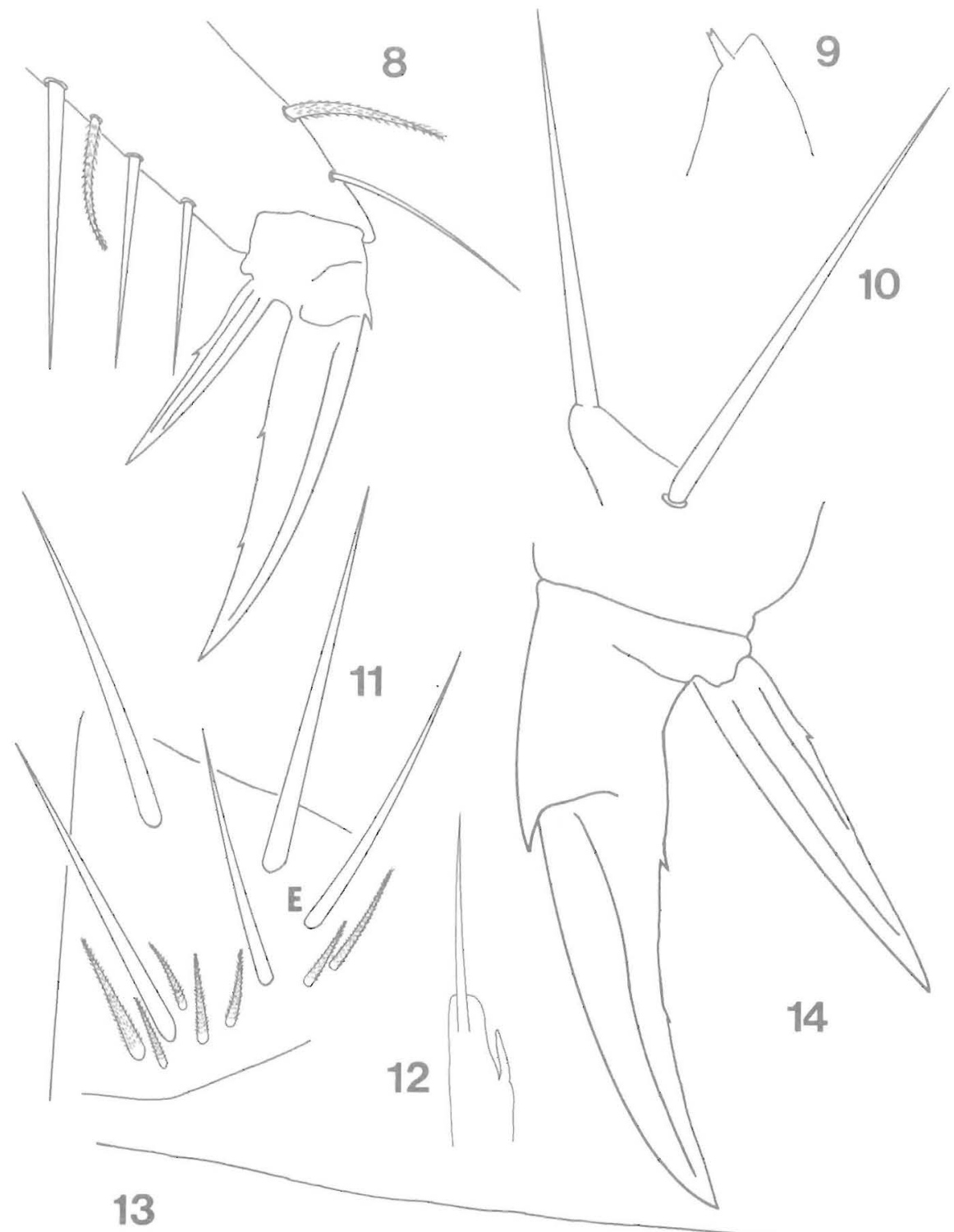

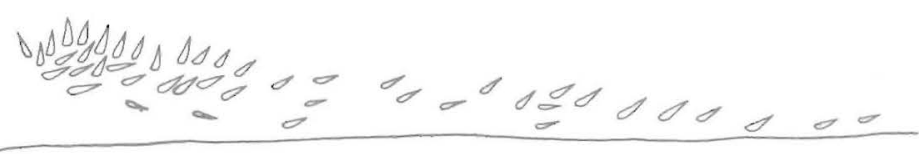

Plate II, Figs. 8-13-D. meruensis, Fig. 14-D. longicornis. 8. Metathoracic claws. 9. Apex of Ant. 6 with pin seta. 10. Maxillary palp. 11. Chaetotaxy of labial triangle. 12. Differentiated seta of outer labial papilla. 13. Arrangement of dental spines, dorsolateral view. 14. Metathoracic claws. 


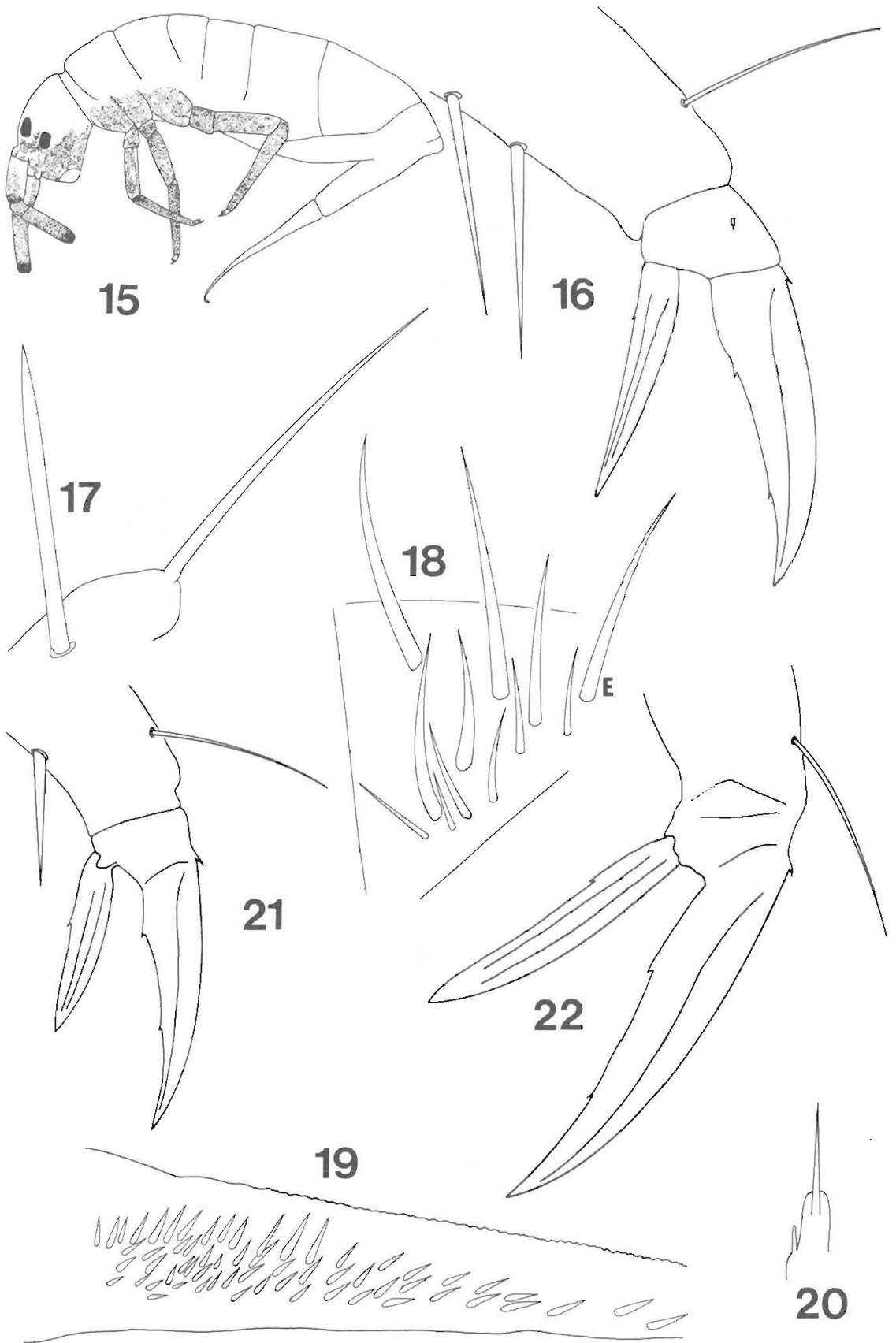

Plate III, Figs. 15-20-D. orientalis, Fig. 21-D. assimilis, Fig. 22-D. spinosus. 15. Habitus and distribution of violet pigment. 16. Metathoracic claws. 17. Maxillary palp. 18. Chaetotaxy of labial triangle. 19. Arrangement of dental spines, dorsolateral view. 20. Outer labial papilla with its differentiated seta. 21. Metathoracic claws. 22. Mesothoracic claws. 

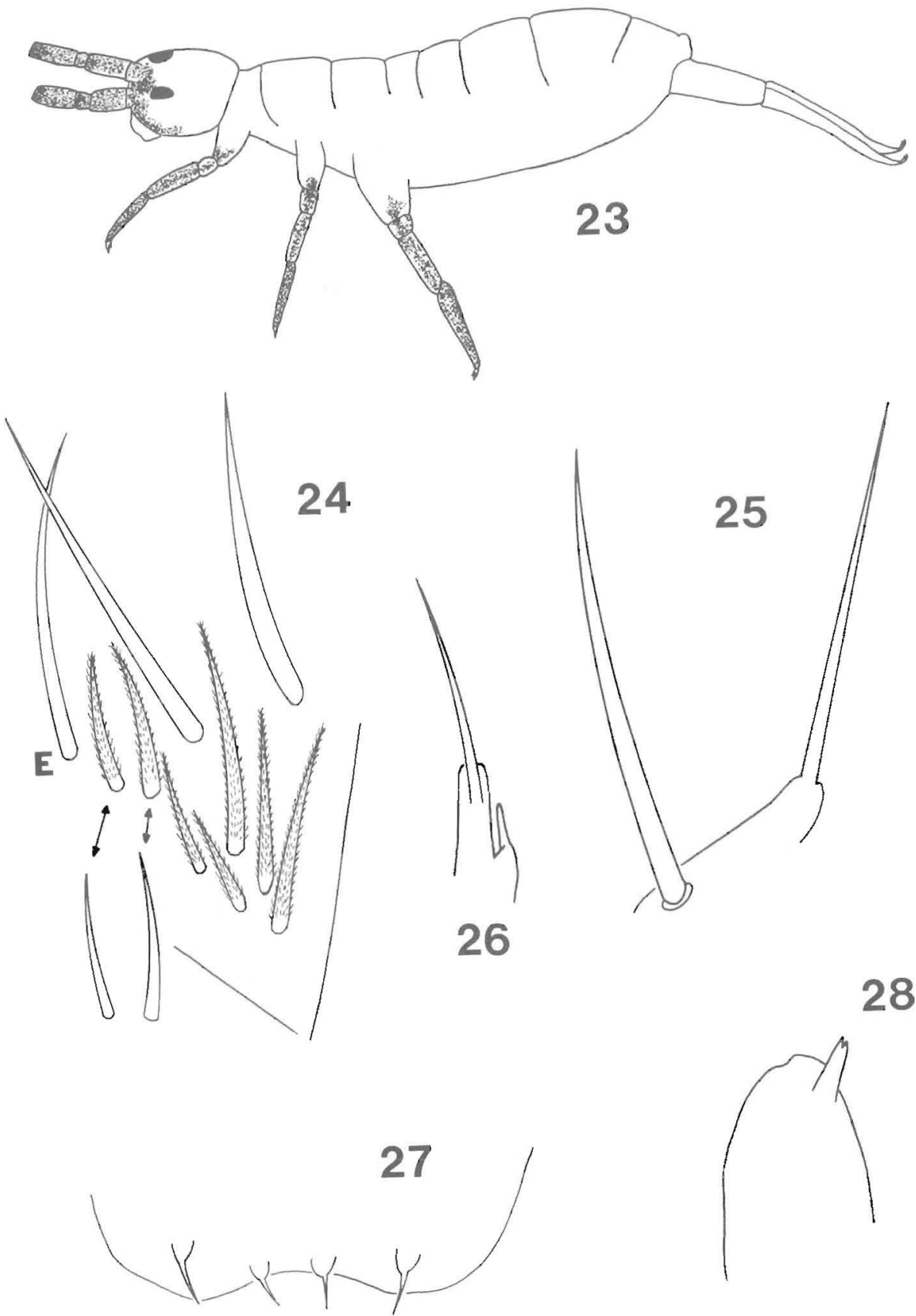

Plate IV, Figs. 23-28-D. inermodentes. 23. Habitus and distribution of violet pigment. 24. Chaetotaxy of labial triangle, setae indicated by arrows may be smooth or cilated. 25. Maxillary palp. 26. Outer labial papillae (type I). 27. Labral papillae (type I). 28. Pin seta on apex of Ant. 6. 

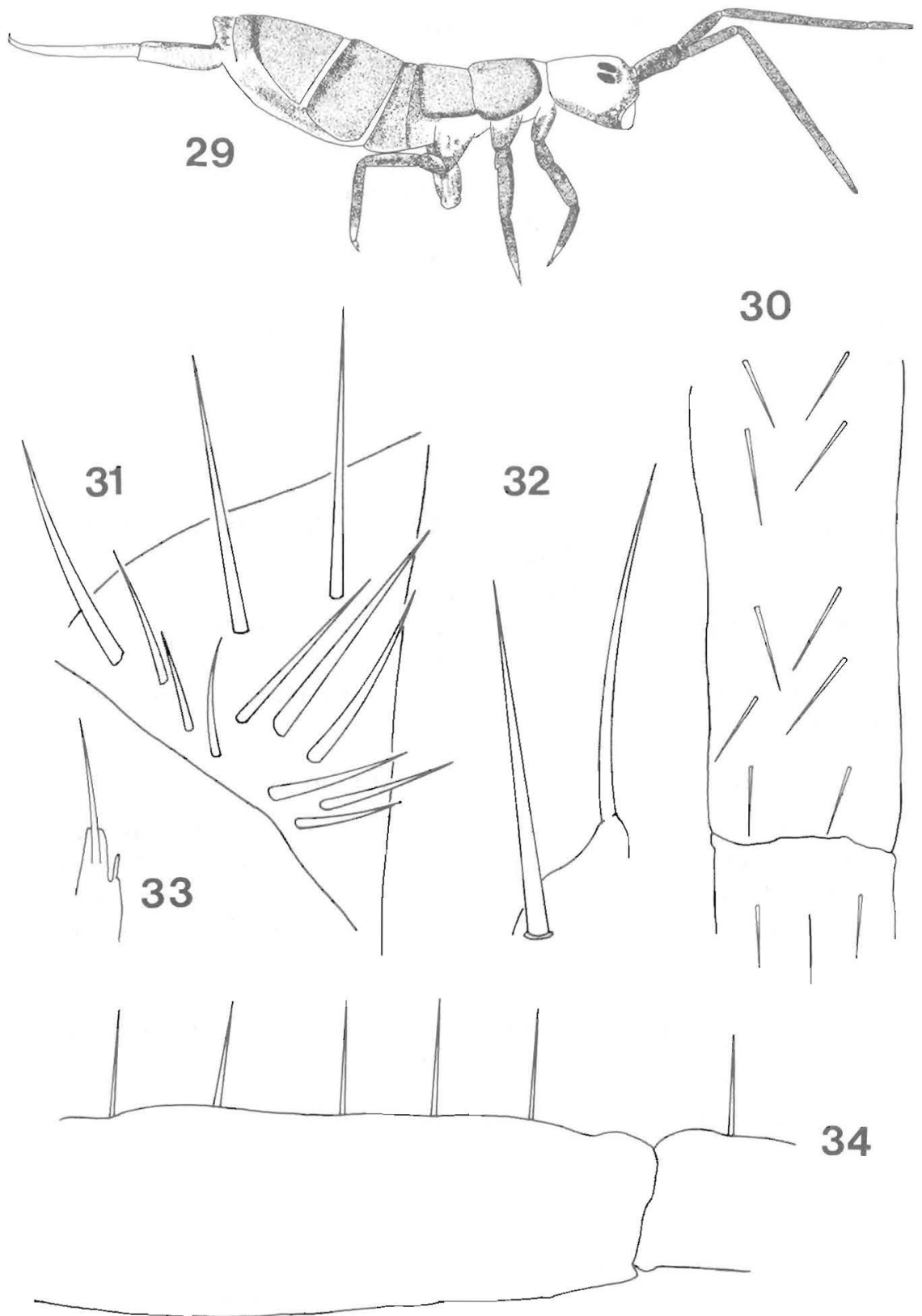

Plate V, Figs. 29-34-D. solomonensis. 29. Habitus and distribution of violet pigment. 30. Distribution of smooth erect setae on dorsum of manubrium and proximal portion of dentes, dorsal view. 31. Chaetotaxy of labial triangle. 32. Maxillary palp. 33. Outer labial papilla. 34 . Distribution of smooth erect setae on manubrium and proximal portion of dentes, lateral view. 
Dorsal body macrochaetotaxy as in figure 6. Furcula apparently without smooth setae. Dental spine arrangement as in figure 7, 10-14 spines in a single row.

\section{Diagnosis}

The species comes closest to D. gracilis Schött (11) and D. colombiensis Mari Mutt (6). From the first it may be separated by the chaetotaxy of Th. 3, relative position of the A group of head macrochaetae, absence of spines on outer margin of dentes, and by the shape of the tenent hair. From $D$. colombiensis, the new species may be distinguished in addition, by the number of $\mathrm{P}$ setae on the head, type of labral papillae, presence of scales on the base of the labium of colombiensis, and by the number of spines on the inner margin of the dentes.

\section{Material Examined}

Ivory Coast, Reserve du Banco, Aug. 22, 1945, R. Paulian and C. Delamare Deboutteville. Holotype and 1 paratype. As preceding, but collected July 26, 1 paratype. As preceding, but collected Aug. 24, legs and furcula of a paratype. As preceding, but collected June 29, 1 paratype.

One paratype from the second locality is in the author's collection, all other specimens are in the Museum National d'Histoire Naturelle, Brunoy, France.

\section{Dicranocentrus meruensis WAHLGREN 1908 (14)}

Color pattern strikingly variable within and between populations (figs. 35-36). Pin seta present (fig. 9). Labral papillae of type I, as in $D$. delamarei. Chaetotaxy of labial triangle as in figure 11. Subapical seta of maxillary palp longer than apical seta (fig. 10). Differentiated seta of outer labial papilla as in figure 12. Setae of postlabial quadrangle (PQL) smooth, most other setae of venter of head smooth. Claws as in figure 8 . Dorsum of manubrium and dorsal proximal portion of dentes with smooth setae. Dental spine arrangement as in figure 13.

\section{Material Examined}

In addition to that listed in (6): Ethiopia, Omo, Camp III de l'Elgon, station 18, 3,500 m, Jan. 5, 1933, R. Jeannel. Holotype of $D$. jeanneli Delamare Deboutteville (2), 30 specimens of the light form (fig. 36) and five of the dark form (fig. 35). Many other specimens are at and were collected in the vicinities of the Omo at the following stations: 8, 15, 17, 18, 20, 31, 34, 39, 41a, 55, 55a and 58 between Jan. 22, 1912 and March 30, 1912; Nov. 11, 1932 and March 23, 1933, and on Aug. 26, 1945. Specimens were collected by R. Jeannell, R. Paulian, and C. Delamare Deboutteville. All this material is in the Museum National d'Histoire Naturelle, Brunoy, 

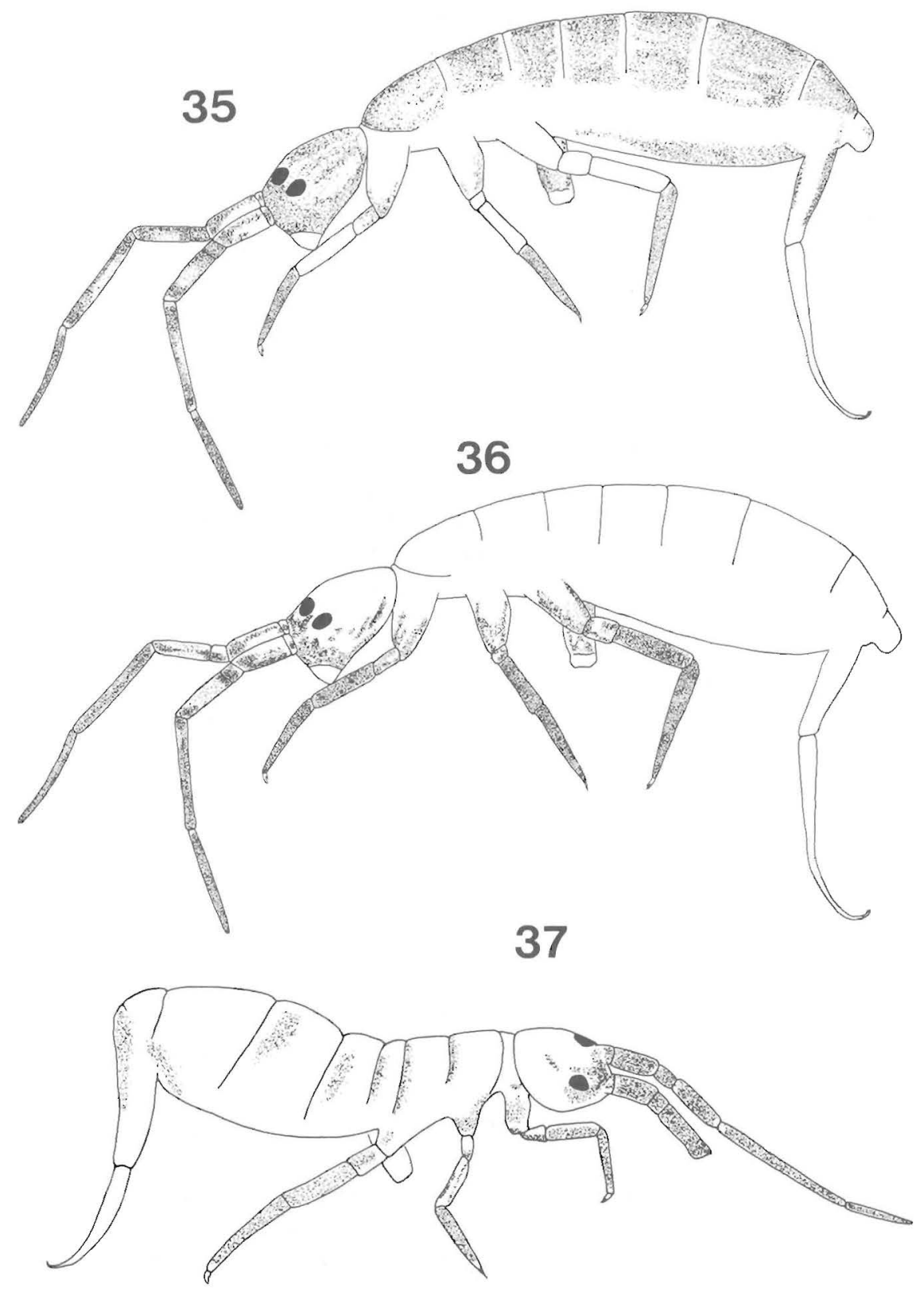

Plate VI, Figs. 35-37. 35-36. D. meruensis-habitus and distribution of violet pigment in the dark and light forms. 37. D. longicornis-habitus and distribution of violet pigment. 
France, except for five specimens of the dark form and five of the light form which are in the author's collection.

\section{Comments}

Although $D$. jeanneli was described from a single specimen, the material on loan from Brunoy contains 40 specimens bearing this name, taken at the type locality, and with the same collection data as the holotype, but not labeled as paratypes. The study of several of these specimens confirmed the synonymy between jeanneli and meruensis proposed by Mari Mutt (6).

\section{Dicranocentrus longicornis (CARPENTER)}

Heteromuricus longicornis Carpenter 1916 (1):36 Salmon 1954 (9) 122.

Dicranocentrus longicornis (Carpenter). Handschin (4):27.

Habitus and distribution of violet pigment as in figure 37. Setae of maximillary palp long, similar in length and shape. Posterior row of labial triangle with 1 ciliated, 2 smooth setae, and 4 sockets suggesting presence of scales. Only 2 setae remain on venter of head, both smooth. Setae A of head arranged as in D. assimilis (Mari Mutt (6):43, fig. 69). Structure of metathoracic claws as in figure 14. Macrochaetae of Abd. 4 arranged as in D. orientalis (Mari Mutt (6):47, fig. 93), but without inner posterior seta. No smooth setae on furcula. Dental spine arrangement as in $D$. platensis (Izarra (5):538, fig. 6).

\section{Material Examined}

Seychelles Islands, Mahé, BM 1916:183, 1 paralectotype deposited at the British Museum (Natural History).

\section{Dicranocentrus stachi (DENIS)}

Heteromurus (Heteromuricus) stachi Denis 1925 (3):265.

Heteromuricus stachi Denis. Salmon 1964 (10):477.

Dicranocentrus stachi (Denis). Handschin (4):23. Womersley (15):472

Mari Mutt (7) has discussed the taxonomic status of this species based on the literature, and concluded that Denis' species belonged in Heteromurus.

The holotype (and only specimen) of this species has arrived from the Museum National d'Histoire Naturelle, Brunoy, France. Its second antennal segment is clearly subsegmented resulting in six-segmented antennae and membership in Dicranocentrus. Dicranocentrus stachi is probably a synomyn of $D$. meruensis Wahlgren. Distribution of violet pigment in stachi corresponds to that of the dark form of meruensis, both species possess similar claw structure, present rows of smooth setae along the inner margin of the tibiotarsi, and occur in Ethiopia. I have not synony- 
myzed these names because it is impossible (except by dissection of the holotype) to determine if dental spines are present in stachi.

The only details added to the descriptions of D. assimilis Schött 1927 (12):24 and D. spinosus Prabhoo 1971 (8):32 are the structures of their claws (figs. 21, 22).

\section{Dicranocentrus orientalis MARI MUTT 1979 (6):67}

Habitus and distribution of pigment as in figure 15. Labral papillae of type I. Chaetotaxy of labial triangle as in figure 18. Subapical seta of maxillary palp clearly differing in shape from apical seta (fig. 17). Differentiated seta of outer labial papilla as in figure 20. All setae of venter of head smooth. Structure of claws as in figure 16. Dorsum of manubrium and dorsal proximal portion of dentes with smooth setae. Arrangement of dental spines as in figure 19.

\section{Dicranocentrus inermodentes (UCHIDA)}

Mesira inermodentes (Uchida) 1944 (13):7.

Dicranocentrus inermodentes (Uchida). Mari Mutt (6):67.

Habitus and pigmentation as in figure 23. Ant. 5 about $1.2 \times$ length of Ant. 6 (Uchida (13):8, fig. 2). Pin seta as in figure 28, observed on apex of regenerated Ant. 5. Labral papillae of type I (fig. 27). Chaetotaxy of labial triangle as in figure 24 , posterior row with all setae ciliated or with both smooth setae and ciliated setae. Setae of maxillary palp as in figure 25. Differentiated seta of outer labial papilla as in figure 26. All setae of venter of head smooth. Furcula without smooth setae.

\section{Dicranocentrus solomonensis MARI MUTT 1979 (6):68}

Habitus and distribution of pigment as in figure 29. Pin seta very small. Labral papillae of type I. Chaetotaxy of labial triangle as in figure 31, posterior row up to E with 7-9 setae. Differentiated seta of outer labial papilla as in figure 33. Setae of maxillary palp as in figure 32. All setae of venter of head smooth. Dorsum of manubrium and dorsal proximal portion of dentes with smooth setae (fig. 30, 34). Chaetotaxy of Abd. 2 (Mari Mutt (6):47, fig. 94) contant. Abd. 4 of 3 specimens with a fifth seta near anterior corner of segment.

\section{Dicranocentrus lawrencei MARI MUTT 1979 (6):66}

All complentary notes in the preceding description apply as well to this species except that Abd. 4 of some specimens presents a fifth seta near center of quadrangle. Both species may be separated by the chaetotaxy of Abds. 1-2, pigmentation, and geographic distribution (Mari Mutt (6): $6)$. 


\section{RESUMEN}

La especie nueva Dicranocentrus delamarei, proveniente de la Costa del Marfil, se describe y se diferencia de sus parientes más cercanos $D$. gracilis Schott y $D$. colombiensis Mari Mutt. Se discute el status taxonómico de $D$. stachi (Denis), especie que había sido colocada en otros dos géneros. Se añaden detalles a las descripciones de las siguientes especies africanas u orientales de Dicranocentrus: meruensis, longicornis, assimilis, orientalis, inermodentes, solomonensis, lawrencei, y spinosus.

\section{LITERATURE CITED}

1. Carpenter, G. H., 1916. The Apterygota of the Seychelles, Proc. Roy. Irish Acad., Sect. B., 33: 1-70 plates.

2. Delaware Deboutteville, C., 1945. Mission scientifique de l'Omo. Faune des terriers des rats-taupes. III. Collemboles, Mém. Mus. Nat. Hist. Nat., (2), 19(1): 31-40.

3. Denis, J. R., 1925. Sur les Collemboles du Museum de Paris, II., Ann. Soc. Entomol. France, 94: 261-290.

4. Handschin, E., 1929. Collembola from Abyssinia, Trans. Entomol. Soc. London, 77: 1528.

5. Izarra, D. C. de, 1972. Alloscopus platensis, una nueva especie de La Plata, Provincia de Buenos Aires (Collembola, Entomobryidae), Physis, 31: 537-539.

6. Mari Mutt, J. A., 1979. A revision of the genus Dicranocentrus Schott (Insecta: Collembola: Entomobryidae), Agri. Exp. Stn. Univ. P.R. Bull. 259.

7. - 1980. On the taxonomic status of Strongylonotus MacGillivray and Heteromuricus Imms (Collembola: Entomobryidae), Rev. Ecol. Biol. Sol, 16(4): 541-546.

8. Prabhoo, N. R., 1971. Soil and litter Collembola of South India. I. Arthropleona, Orient. Ins., 15: 1-46.

9. Salmon, J. T., 1954. Orchesellini (Collembola) of East Africa, Ann. Mag. Nat. Hist., Ser. $12,7: 122-127$.

10. - 1964. An Index to the Collembola, Roy. Soc. New Zealand Bull. 7.

11. Schött, H. G., 189:3. Beiträge zur kenntnis der insektenfauna von Kamerun, Bihang. till K. Sven. Vetenskapsakad. HandI., 19: 5-28.

12. — 1927. Kamerunische Collembolen, Meriu. Linkopings hogre allm. laroverks redugorelse.

13. Uchida, H., 1944. Collembola von Mikronisien, Bull. Tokyo Sci. Mus., 17: 1-23.

14. Wahlgren, E., 1980. Wissenschaftliche Ergebnisse der Schwedischen Zoologischen $7_{\text {...- }}$ pedition nach dem Kilimandjaro, dem Meru den umgebenden massaisteppen Deutsch-Ostafrikas 1905-1906 unter leitung von P Prof. Dr. Yngve Sjostedt. 18. Apterygogenea, 1. Collembola pp. 1-10.

15. Womersley, H., 1934. On some Collembola-Arthropleona from South Africa and Southern Rhodesia, Ann. South African Mus., 3(30): 44I-475. 